\title{
Unique Biochemical and Mineral Composition of Whale Ear Bones
}

Sora L. Kim ${ }^{1, \star}$

J. G. M. Thewissen ${ }^{2}$

Morgan M. Churchill ${ }^{1,3}$

Robert S. Suydam ${ }^{4}$

Darlene R. Ketten ${ }^{5}$

Mark T. Clementz ${ }^{1,3}$

${ }^{1}$ Department of Geology and Geophysics, University of Wyoming, 1000 East University Avenue 3006, Laramie, Wyoming 82071; ${ }^{2}$ Department of Anatomy and Neurobiology, Northeast Ohio Medical University, Rootstown, Ohio 44272; ${ }^{3}$ Program in Ecology, University of Wyoming, 1000 East University Avenue 3622, Laramie, Wyoming 82071; ${ }^{4}$ Department of Wildlife Management, North Slope Borough, Barrow, Alaska 99753; ${ }^{5}$ Biology Department, Woods Hole Oceanographic Institution, Woods Hole, Massachusetts 02543; and Department of Otology and Laryngology, Harvard Medical School, Boston, Massachusetts 02114

Accepted 2/21/2014; Electronically Published 6/3/2014

Online enhancements: appendix tables.

\section{ABSTRACT}

Cetaceans are obligate aquatic mammals derived from terrestrial artiodactyls. The defining characteristic of cetaceans is a thick and dense lip (pachyosteosclerotic involucrum) of an ear bone (the tympanic). This unique feature is absent in modern terrestrial artiodactyls and is suggested to be important in underwater hearing. Here, we investigate the mineralogical and biochemical properties of the involucrum, as these may hold clues to the aquatic adaptations of cetaceans. We compared bioapatites (enamel, dentine, cementum, and skeletal bone) of cetaceans with those of terrestrial artiodactyls and pachyosteosclerotic ribs of manatees (Sirenia). We investigated organic, carbonate, and mineral composition as well as crystal size and crystallinity index. In all studied variables, bioapatites of the cetacean involucrum were intermediate in composition and structure between those of tooth enamel on the one hand and those of dentine, cementum, and skeletal bone on the other. We also studied the amino acid composition of the cetacean involucrum relative to that of other skeletal bone. The central involucrum had low glycine and hydroxyproline concentrations

\footnotetext{
${ }^{*}$ Corresponding author. Present address: Department of Geophysical Sciences, University of Chicago, Chicago, Illinois 60637; e-mail: sora@uchicago.edu.

Physiological and Biochemical Zoology 87(4):576-584. 2014. (C) 2014 by The University of Chicago. All rights reserved. 1522-2152/2014/8704-3109\$15.00. DOI: $10.1086 / 676309$
}

but high concentrations of nonessential amino acids, unlike most bone samples but similar to the tympanic of hippos and the (pachyosteosclerotic) ribs of manatees. These amino acid results are evidence of rapid bone development. We hypothesize that the mineralogical and amino acid composition of cetacean bullae differs from that of other bone because of (1) functional modifications for underwater sound reception and (2) structural adaptations related to rapid ossification.

\section{Introduction}

Ancestral cetaceans (whales, dolphins, and porpoises) evolved from land mammals of the order Artiodactyla approximately 50 million years ago. This transition is well documented in the fossil record and indicates many skeletal modifications to accommodate an aquatic lifestyle (reviewed in Thewissen et al. 2009). Modern artiodactyls include pigs, camels, cows, antelope, and also the hippo. Hippos are generally assumed to be the modern terrestrial species most closely related to cetaceans (Spaulding et al. 2009). Among extinct artiodactyls, Raoellidae from the early-to-middle Eocene of India ( 50-45 Ma; Thewissen et al. 2007) are the closest relatives of cetaceans. One of the earliest and most important modifications in the transition to water took place in the bones of the cetacean ear, specifically, the tympanic bone (also called the bulla; fig. 1; e.g., reviewed in Ketten 1992 and Nummela et al. 2007). The cetacean bulla developed an enlarged medial lip, the involucrum, which is also present in raoellids but not in other artiodactyls (Thewissen et al. 2007). The enlargement of the involucrum involves both a thickening caused by the addition of bone (pachyostosis) and an increase of bone density (osteosclerosis). Studies of material properties of the involucrum have shown differences from other mammalian bone (Carter and Hayes 1976; Currey 1999; Ketten 2000; de Buffrénil et al. 2004; Thewissen et al. 2007; Buckley et al. 2012), but there are no detailed comparisons of mineral and amino acid composition among artiodactyls or in cetaceans.

Bone composition and biochemistry dictate strength and function, but evolution may constrain which morphologies originate. The density and mechanical properties of bone affect the relative proportions of organic, mineral, and carbonate content (Currey 1999). The primary organic component of bone is collagen, and its structure and function are determined by its amino acid composition. For example, proportionately higher concentrations of hydroxyproline and glycine can increase collagen strength and stability: hydroxyproline is relatively insoluble, and glycine provides sites for increased hydrogen bonding (Champe et al. 2008). The mineral portion of 

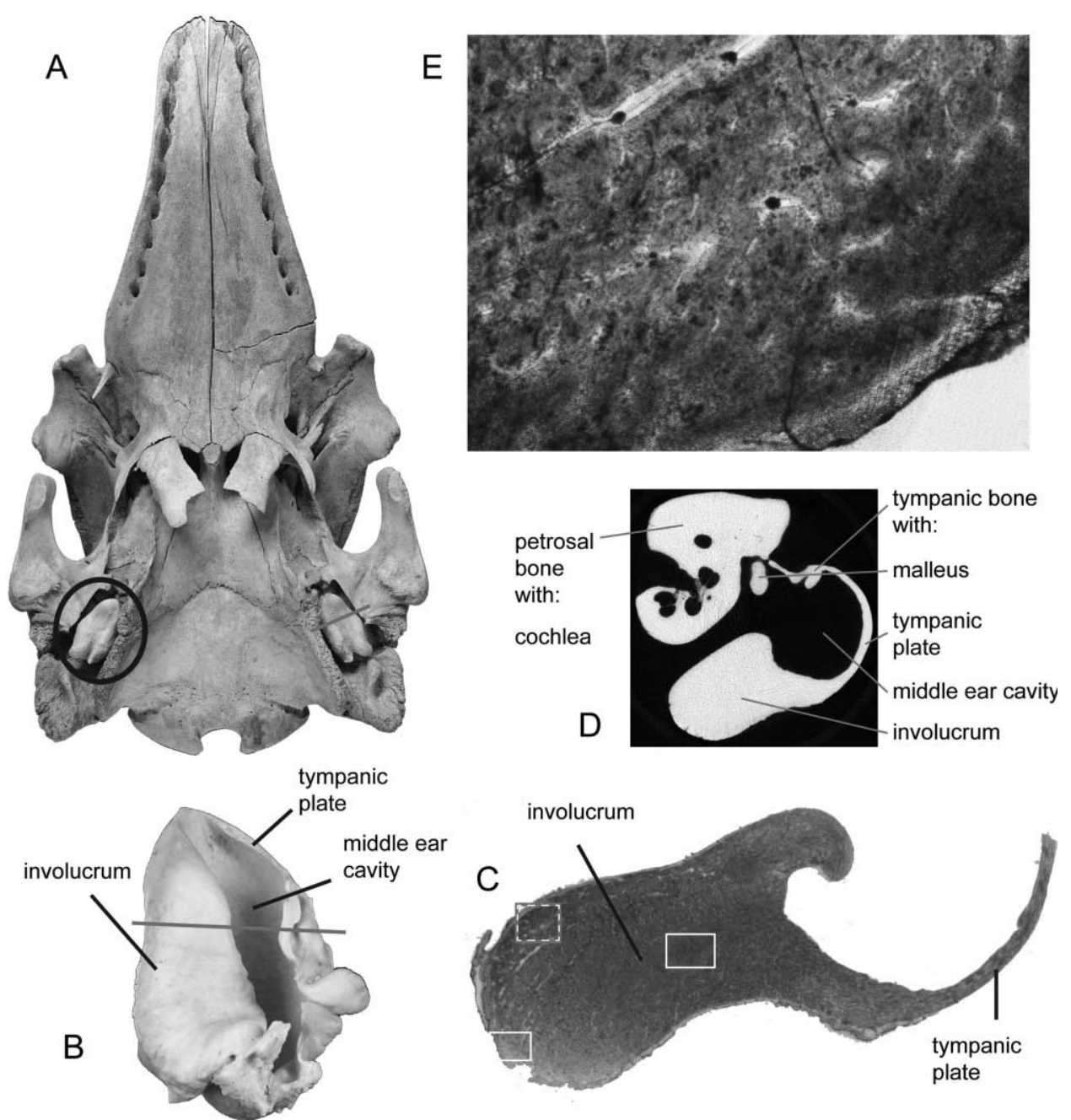

Figure 1. Overview of the cetacean tympanic bone. $A$, Skull of a beluga whale in ventral view, with right tympanic bone circled, to show the general anatomy of the cetacean petrosal and tympanic bone and sampling sites. The petrosal bone cannot be seen; it is covered by the tympanic bone. $B$, Right tympanic bone in dorsal view. $C$, Histological section through tympanic bone, at the level of the horizontal line in $B$; solid rectangles indicate exterior versus central location of samples for this study. $D$, Computerized tomography scan of petrosal and tympanic bones at the level of the horizontal line in $B$. E, Detail of histological section in $C$ (dashed square) under polarized light.

all hard tissues of the body (bone, enamel, dentin, cementum) is a highly substituted biological hydroxylapatite $\left(\mathrm{Ca}_{10}\left[\mathrm{PO}_{4}, \mathrm{CO}_{3}\right]_{6}\left[\mathrm{OH}, \mathrm{CO}_{3}\right]_{2}\right)$ often referred to as bioapatite (El Feki et al. 1999). Although the presence of - $\mathrm{OH}$ groups in bone mineral has been questioned, advanced methods have demonstrated their presence (Rey et al. 1995; Loong et al. 2000; Cho 2003).

The composition of the cetacean involucrum is intermediate between those of enamel and other bioapatites (bone, dentin, and cementum). The combined carbonate and mineral content is $96 \%$ in enamel, $85 \%$ in the involucrum, and $50 \%-70 \%$ in other bioapatites, whereas organic content for these bioapatite groups are 1\%, 9\%, and 20\%-24\%, respectively (Currey 1999; de Buffrénil et al. 2004; Mkukuma 2004; Pasteris et al. 2008). This study explores structural and biochemical traits of pachyostosis and osteosclerosis, comparing the bioapatite of the ce- tacean involucrum to other mammalian bioapatites. To add analytical rigor to our study, we chose a variety of bioapatites (enamel, dentin, and bone) for comparison but limited the taxonomic range of our samples to cetaceans, sirenians, and terrestrial artiodactyls. We compared macro- and nanoscale structure of artiodactyl bioapatites on the basis of material composition (i.e., weight percent organic, carbonate, and mineral; crystallinity; and crystal size) as well as amino acid profiles to link skeletal morphology and evolutionary adaptation.

\section{Methods}

\section{Sampling}

We used the total-evidence phylogeny from Spaulding et al. (2009) as our comparative framework among artiodactyls (fig. 2). Enamel, dentine, cementum, and bone from different por- 


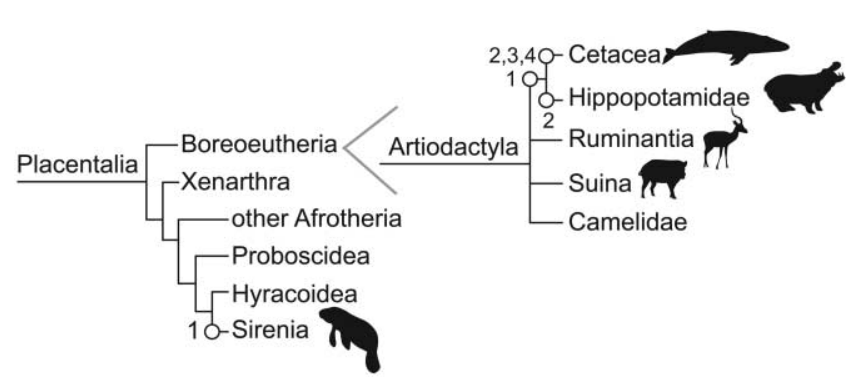

Figure 2. Placentalia phylogeny illustrates the distant relationship between manatees (in Afrotheria) and cetaceans (in Boreoeutheria). Artiodactyla phylogeny was used as a framework for specimens included in this study (indicated with silhouettes; phylogeny modified from Spaulding et al. 2009). Traits: (1) pachyosteosclerotic bone, (2) underwater hearing, (3) pachyosteosclerotic involucrum, and (4) fully aquatic lifestyle.

tions of the skeleton (rib, femur, vertebra) were sampled from multiple taxa within Artiodactyla to quantify the material properties of different bioapatites (table A1; tables A1-A3 available online). Bullae from aquatic (cetaceans [one odontocete and four mysticete species]), semiaquatic (common hippopotamus Hippopotamus amphibius), and terrestrial artiodactyls (two ruminant and one suid species) were also sampled for comparison. Because cetacean bullae were subsampled from the involucrum, we distinguished between the exterior and central areas (fig. 1C). The only nonartiodactyl bones sampled were manatee ribs, which were included because of their pachyosteosclerotic condition. We compared all samples to an inhouse standard (manatee rib bone roasted and recrystallized at $700^{\circ} \mathrm{C}$ ), which served as an extreme end member of highly crystalline bioapatite. All samples were powdered and homogenized by means of a Dremel (Racine, WI) drill with a diamond tip and a mortar and pestle.

\section{Loss-on-Ignition (LOI) Analysis}

LOI analysis allowed us to measure the organic, carbonate, and mineral content of bioapatites. Samples were weighed $(\sim 100$ mg for all samples except those from the odontocete Delphinapterus and Hippopotamus, which, because of sample limitations, had initial weights of $\sim 5 \mathrm{mg}$ ) and roasted at $110^{\circ} \mathrm{C}$ to remove water and obtain a dry weight. Organics and carbonates were removed sequentially from each sample during combustion at $500^{\circ}$ and $1,000^{\circ} \mathrm{C}$, respectively (Heiri et al. 2001). During combustion, the oven was gradually heated or cooled at $3.5^{\circ} \mathrm{C}$ per minute, and the target temperature was held for $1 \mathrm{~h}$. Carbonate content was stoichiometrically calculated on the basis of $\mathrm{CO}_{2}$ loss at $1,000^{\circ} \mathrm{C}$. Mineral content was calculated on the basis of loss of organic and carbonate material. Two reference materials were analyzed in triplicate during each LOI analysis, and the standard error associated with the organic, carbonate, and mineral content among all runs was $<0.6 \%(n=11)$. Data were compared via nonparametric tests (Kruskal-Wallis test) because of the small and unequal sample sizes within each bioapatite group. We adjusted $\alpha=0.05$ on the basis of a Bonferroni correction for three comparisons of the data, which resulted in $\alpha=0.017$. All quantitative analyses were performed in $\mathrm{R}$, version 2.12.1 (R Core Development Team 2008). Previous studies have compared the macrocomposition of cetacean bullae to that of other skeletal bones, but mineral content was determined through a variety of methods (Currey 1999; Mkukuma 2004; Nummela et al. 2004; Pasteris et al. 2004), thus confounding the comparison of organic, carbonate, and mineral components. Therefore, we sampled an extensive range of bioapatites but could not compare our results to those of previous investigations.

\section{X-Ray Diffraction (XRD) Analysis}

Crystallinity and crystal size of different bioapatites belonging to aquatic, semiaquatic, and terrestrial artiodactyls were assessed by XRD analysis of one sample of each (table A1; enamel [ruminant: Bos], dentine [odontocete: Physeter], bone [ruminant cortical bone: Antilocapra; manatee pachyosteosclerotic bone: Trichechus; suid bulla: Sus; odontocete bulla: Delphinapterus; and mysticete bulla: Eschrichtius]). Powdered bioapatite (>10 mg) was analyzed with a SCINTAG XDS 2000 (Cupertino, CA) diffractometer with a rotating sample holder and a 2.2$\mathrm{kW}$ sealed copper radiation source (Department of Geology and Geophysics Materials Characterization Laboratory, University of Wyoming). Individual samples were analyzed over 3 $\mathrm{h}$, with measurements collected from $2^{\circ}$ to $70^{\circ} 2 \theta$ at $0.2^{\circ}$ intervals. Crystallinity index $(\mathrm{CI})$ is a measure of order within a crystal lattice that reflects crystallite size, strain, and composition of a given material (Shemesh 1990). CI was calculated as

$$
\mathrm{CI}=\frac{\left(H_{112}+H_{300}+H_{202}\right)}{H_{211}},
$$

where $H$ equals the height of the given peak reflection minus the baseline value between peaks (Person et al. 1995). In addition, crystallite size was determined with the Sherrer equation (Danilchenko et al. 2002) and is reported in angstroms $(\AA)$.

\section{Amino Acid Analysis}

Amino acid composition was determined for a suite of bones from five aquatic (one odontocete [Delphinapterus adult] and four mysticetes [one Balaena fetus and Megaptera, Balaenoptera, and Eubalaena adults]), one semiaquatic (Hippopotamus adult), and four terrestrial (two Antilocapra and two Sus, all adult) artiodactyls and one nonartiodactyl (Trichechus subadult). Bone $(\sim 10 \mathrm{mg})$ was decalcified in $10 \mathrm{~mL}$ of $0.25 \mathrm{M}$ ethylenediaminetetraacetic acid (EDTA). Samples were agitated for $60 \mathrm{~s}$ and rested at room temperature for 3-5d, until organics remained suspended in solution. Then, the EDTA was removed and samples were rinsed 10 times with deionized water (with an overnight pause between rinses 5 and 6) and freeze-dried for $24 \mathrm{~h}$. The remaining protein was hydrolyzed at $110^{\circ} \mathrm{C}$ for $17 \mathrm{~h}$ in $1 \mathrm{~mL}$ of $6 \mathrm{~N} \mathrm{HCl}$ (glass tubes were combusted before 
use and flushed with $\mathrm{N}_{2}$ before sealing with a Teflon-lined cap). Of this hydrolysate, $100 \mu \mathrm{L}$ was transferred to a new vial, dried, dissolved in $10 \mathrm{mM} \mathrm{HCl}$, and sonicated. Insoluble material was pelleted during high-speed centrifugation for $5 \mathrm{~min}$. Finally, $10 \mu \mathrm{L}$ of supernatant, $70 \mu \mathrm{L}$ of borate buffer, and $20 \mu \mathrm{L}$ of Waters (Milford, MA) AccQ-Tag reagent were mixed and incubated at room temperature for $1 \mathrm{~min}$, then at $55^{\circ} \mathrm{C}$ for 10 min. Samples $(10 \mu \mathrm{L})$ were analyzed in duplicate with a Waters Acquity UPLC at the University of Wyoming Macromolecular Analysis Core Facility. Replicates of an amino acid standard determined a coefficient of variation $<1 \%$. The pattern of correlation between the relative molar abundances of individual amino acids was assessed with a principal-component analysis (PCA) performed in R with the "VEGAN: Community Ecology" package (Dixon 2003; R Development Core Team 2008). Our PCA analysis included data from this study and the mammalian bone collagen compiled in Szpak (2011 and references therein) as row data in the initial Eigen analysis. The amino acids used in the analysis were aspartic acid, hydroxyproline, threonine, serine, glutamic acid, proline, glycine, alanine, valine, methionine, isoleucine, leucine, tyrosine, phenylalanine, lysine, histidine, and arginine.

\section{Results}

A qualitative and quantitative comparison between bioapatites from the cetacean involucrum and those from other bone, cementum, dentine, and enamel showed that organic, carbonate, and mineral contents significantly differed among these bioapatites (fig. $3 A, 3 B$; table 1). Skeletal bone, terrestrial artiodactyl bulla, cementum, and dentine had the greatest organic content and showed the largest variation in this component (fig. 3B). Among bones analyzed, skeletal bone and terrestrial artiodactyl bulla were similar in organic and mineral content but were significantly different in carbonate content (table 1). Organic, carbonate, and mineral contents of terrestrial artiodactyl bullae (including those of the hippo) were significantly different from those of cetacean involucrum specimens (table 1). Cetacean bullae had intermediate organic and mineral content when compared to enamel and all other bioapatites, but cetacean bullae and cementum had similarly high carbonate content (fig. $3 B$; table 1).

A PCA of the relative individual amino acid abundances found compositional differences that describe $93 \%$ of the variation in data along three axes $(71 \%, 15 \%$, and $7 \%$; fig. $3 C$; table A2). Variation on principal components 1 and 2 (PC1 and PC2) is attributed to differences in glycine, hydroxyproline, glutamic acid, aspartic acid, arginine, alanine, and lysine (in descending order of influence). The exterior of the cetacean involucrum is similar to artiodactyl skeletal bones and terrestrial artiodactyl bulla, with increased amounts of glycine, hydroxyproline, and arginine $(\mathrm{PC} 1<0$; fig. $3 \mathrm{C})$. However, the central involucrum from cetacean bulla has increased amounts of glutamic acid, aspartic acid, alanine, and lysine (PC1 values $>0$; fig. $3 C$ ). Other exceptions to this pattern are osteosclerotic and pachyosteosclerotic bone from hippos and man-
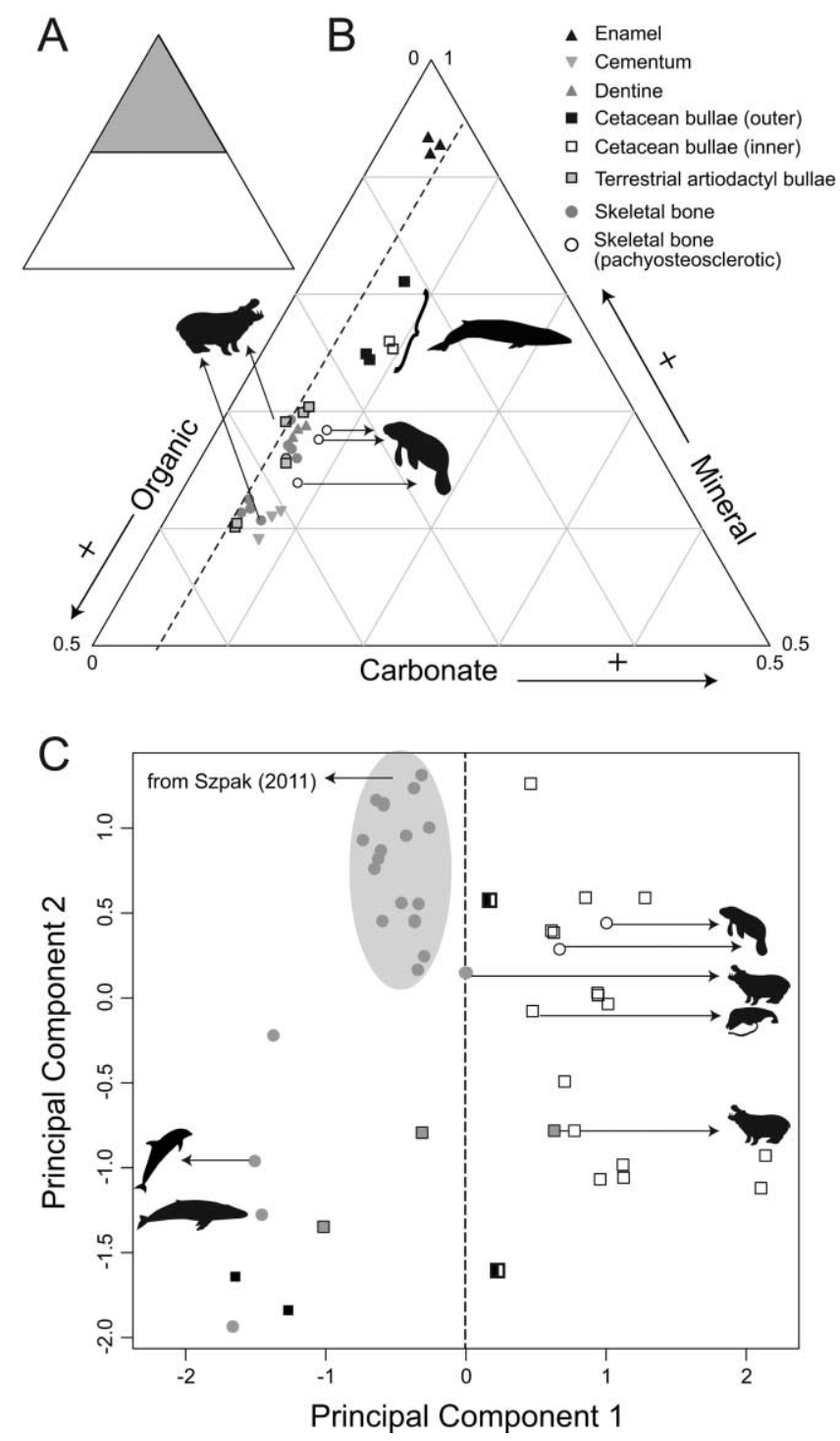

Figure 3. Compositional differences in organic, mineral, and carbonate content $(A, B)$ and amino acid composition among 13 species of artiodactyls and Trichechus manatus. A ternary diagram demonstrates the differences in organic, mineral, and carbonate composition among bioapatites. The portion of the ternary plot relevant for this study is shown in gray $(A)$ and magnified $(B)$. $C$, Relative composition of amino acid abundance is summarized with a principal-components $(\mathrm{PC})$ analysis. Symbols apply to $B$ and $C$; the dashed line is where $\mathrm{PC} 1=0$, the division between skeletal and osteosclerotic bone. Opportunistically sampled bullae chips are depicted as half-filled squares because the exterior involucrum rind is combined with material sampled from the central involucrum of cetacean bullae.

atees, respectively (fig. 3C; table A3). Two cetacean bulla samples with PC1 values intermediate between those for osteosclerotic and pachyosteosclerotic bone and those for other mammalian skeletal bone were opportunistically sampled chips rather than milled samples (fig. 3C). Finally, our amino acid analysis includes one fetal mysticete bulla (Balaena), which groups on the outer margins of the osteosclerotic and pachy- 
Table 1: Summary and statistical comparison of loss-on-ignition data

\begin{tabular}{|c|c|c|c|c|}
\hline Comparison & $N$ & $\%$ organic $(\mathrm{SD})$ & $\%$ carbonate $(\mathrm{SD})$ & $\%$ mineral $(\mathrm{SD})$ \\
\hline Bones & 19 & $28.6(4.1)$ & $6.1(1.1)$ & $65.3(3.8)$ \\
\hline Cementum & 3 & $31.4(1.4)$ & $7.6(.2)$ & $61.0(1.0)$ \\
\hline Dentine & 3 & $25.4(.7)$ & $5.9(.3)$ & $68.7(.5)$ \\
\hline Enamel & 3 & $5.0(2.3)$ & $3.9(.8)$ & $91.1(2.7)$ \\
\hline Cetacean bullae & 6 & $14.0(3.3)$ & $7.9(1.1)$ & $78.1(4.1)$ \\
\hline $\begin{array}{l}\text { Kruskal-Wallis }{ }^{\mathrm{a}} \\
\text { Bones: }\end{array}$ & & $\chi^{2}=21.496 ; P<.0002^{\star}$ & $\chi^{2}=16.698 ; P=.0022^{\star}$ & $\chi^{2}=22.277 ; P<.0001^{\star}$ \\
\hline All skeletal bones & 13 & $28.0(3.4)$ & $6.5(1.1)$ & $65.5(3.2)$ \\
\hline $\begin{array}{l}\text { Terrestrial artiodactyl } \\
\text { bullae }\end{array}$ & 6 & $29.9(5.4)$ & $5.1(.6)$ & $65.0(5.2)$ \\
\hline Kruskal-Wallis $^{\mathrm{b}}$ & & $\chi^{2}=.4932 ; P=.4825$ & $\chi^{2}=5.8532 ; P=.01555$ & $\chi^{2}=.0173 ; P=.8952$ \\
\hline $\begin{array}{l}\text { Terrestrial artiodactyl } \\
\text { bullae }\end{array}$ & 6 & $29.9(5.4)$ & $5.1(.6)$ & $65.0(5.2)$ \\
\hline Cetacean bullae & 6 & $14.0(3.3)$ & $7.9(1.1)$ & $78.1(4.1)$ \\
\hline Kruskal-Wallis $^{\mathrm{b}}$ & & $\chi^{2}=8.3368 ; P<.0039^{*}$ & $\chi^{2}=8.3077 ; P=.0039^{\star}$ & $\chi^{2}=8.3077 ; P<.0039^{*}$ \\
\hline
\end{tabular}

osteosclerotic bones (PC2 $=0.14$; fig. 2C). Our PCA included the mammalian bone amino acid compositions from Szpak (2011), but a PCA limited to our data set reflects the same pattern. With an unpaired $t$-test, we found a significant effect for osteosclerotic and pachyosteosclerotic versus skeletal bone based on PC1 values $\left(t_{46}=10.7, P \ll 0.0001\right)$.

Compositional differences were also reflected in the XRD results, which indicated two distinct patterns (fig. 4). The enamel had sharp, narrow peaks, with large crystallite size (300$400 \AA$ ) and high crystallinity $(\mathrm{CI}=1.47)$. In addition, this sample closely matched the reference, $\mathrm{Ca}_{10}\left(\mathrm{PO}_{4}\right)_{6}(\mathrm{OH})_{2}$, and our highly crystalline end member (manatee rib roasted at $700^{\circ}$ : crystallite size $>1,000 \AA, \mathrm{CI}=1.33$ ). The other terrestrial and semiaquatic artiodactyl bioapatites analyzed had shorter and less distinctive peaks (gray patterns in fig. 4), with smaller crystallite sizes (70-140 $\AA$ ), CI $\approx 0$, and matched reference $\mathrm{Ca}_{5}\left(\mathrm{PO}_{4}\right)_{3} \mathrm{~F}$. The exceptions among the bone XRD patterns were for an odontocete bulla (central and exterior involucrum crystallite sizes $=150-180$ and $140-170 \AA$ and $\mathrm{CI}=1.14$ and 1.18 , respectively) and a mysticete bulla (central and exterior involucrum: crystallite size $=90-100$ and 70-90 $\AA$ and CI = 0.35 and 0.42 , respectively). The mysticete involucrum pattern was most similar to that of the hippo bulla, whereas the odontocete involucrum pattern had peak distinctions similar to those for enamel but with less resolution and smaller peak heights (fig. 4).

\section{Discussion}

A comparison among artiodactyl and pachyosteosclerotic bioapatite reveals differences in structural composition that are not simply inherent qualities of increased bone density. Although pachyosteosclerotic (manatee ribs) and osteosclerotic (hippo bulla and occipital condyle) bones have carbonate, or- ganic, and mineral contents similar to those of artiodactyl skeletal bone, cetacean bullae have a unique composition that is intermediate between enamel, on one hand, and all other bioapatites on the other (Currey 1999; Mkukuma 2004; Wopenka and Pasteris 2005; fig. 3B). In contrast, amino acid compositions for all dense bone types (except the exterior portion of cetacean bullae) were similar and, unexpectedly, distinct from those of other skeletal bones or those of tympanics sampled from terrestrial artiodactyls (fig. 3C). We hypothesize that differences in structural composition between the involucrum of cetacean bullae and other bones of artiodactyls are related to functional modifications for underwater sound conduction as well as structural constraints inherent to rapid ossification during prenatal development (Cozzi et al. 2012). Our results demonstrate amino acid compositional differences among bone types related to function, as previously predicted (Currey 1979, 1999; Buckley et al. 2012).

\section{Modifications Related to Function}

Terrestrial mammal auditory systems are optimized for the reception of sound in air via an outer and middle ear that transfers sound energy to a liquid-filled labyrinth of the inner ear. In water, because of the differences in impedance between the media transmitting sound (water and air), a land ear will function poorly (Wartzok and Ketten 1999; Nummela et al. 2004). Cetaceans have altered the terrestrial hearing design of artiodactyls for underwater hearing by isolating the tympanoperiotic complex (to different degrees) from the skull and inflating the tympanic bulla involucrum (Ketten 1992 and references therein; de Buffrénil et al. 2004; Nummela et al. 2007; Hemilä et al. 2010). First, in odontocetes, sound is primarily conducted through fat bodies within the jaw (reviewed in Ketten 1992; 


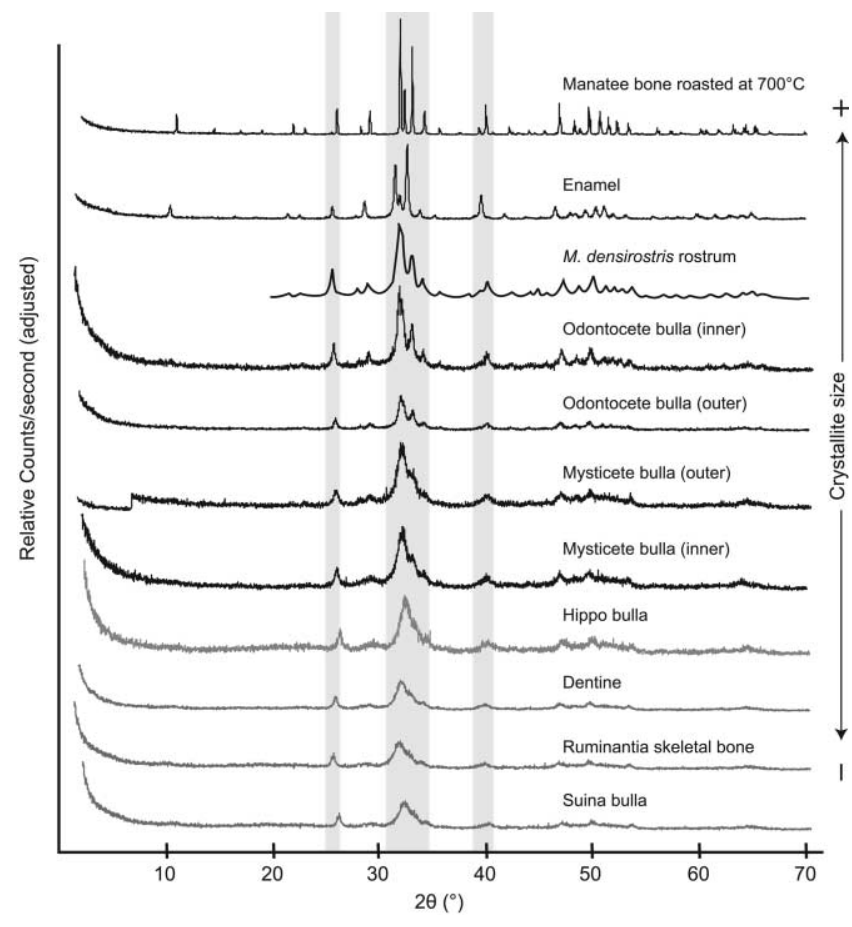

Figure 4. X-ray diffraction (XRD) patterns for select bioapatites are arranged from largest (top) to smallest (bottom) crystallite size. Black patterns follow the standard $\mathrm{Ca}_{10}\left(\mathrm{PO}_{4}\right)_{6}(\mathrm{OH})_{2}$, whereas the gray patterns are more similar to $\mathrm{Ca}_{5}\left(\mathrm{PO}_{4}\right)_{3} \mathrm{~F}$. The Mesoplodon densirostris rostrum was analyzed by Rogers and Zioupos (1999) and included in this figure because the XRD pattern demonstrates the hypermineralization of this bone. Vertical gray bands indicate peaks associated with bioapatite.

Koopman et al. 2006). There is preliminary evidence of fatty sound reception in minke whales (Balaenoptera acutorostrata) based on computerized tomography and magnetic resonance imaging, which show ear fats associated with the mysticete tympanoperiotic complex (Yamato et al. 2012); however, the mechanism for hearing in mysticetes remains unclear. All cetaceans have a large, stiff "sound-collecting area" with increased size, density, and mineralization of the pachyosteosclerotic involucra of their bullae (Nummela et al. 1999, 2007; Hemilä et al. 2010), but the involucra of odontocete bullae have increased density and mineralization compared to those of mysticetes (Nummela et al. 2007; fig. 3B). This variation in structural composition suggests that the pachyosteosclerotic condition is necessary for underwater hearing, but the extent of osteosclerosis affects the modulus of elasticity (Currey 1979) and may improve high-frequency or directional hearing. In contrast to cetaceans, hippos have limited underwater hearing capabilities (Barklow 2004); their tympanic bullae are less dense than those of cetaceans, and hippos rely more on bone conduction through the lower jaw (Currey 1999; O'Leary et al. 2012). A detailed analysis of hippo bulla volume and density found a pachyostotic condition without osteosclerosis (Spaulding et al. 2009; O'Leary et al. 2012), which is also reflected in the PCA results of amino acid composition (fig. 3C).
The bullae of terrestrial artiodactyls did not differ in composition from skeletal bone (table 1; fig. 3B, 3C). Our results indicate no significant differences in the macro- or nanoscale properties of terrestrial artiodactyl bullae and skeletal bone, based on three independent lines of evidence: (1) terrestrial artiodactyl bullae and skeletal bone organic, carbonate, and mineral contents are not significantly different (table 1; fig. $3 B$ ); (2) collagen associated with these bioapatites has high hydroxyproline and glycine content, with $\mathrm{PC} 1$ values of $<0$, in contrast to pachyostotic and osteosclerotic bone, including the involucra of cetacean bullae (fig. 3B); and (3) terrestrial artiodactyl bullae and skeletal bone have low crystallinity, with poorly resolved peak shapes based on XRD patterns (fig. 4).

Cetacean bullae may have unique compositional traits because their function and stress differ from those of skeletal bones. This functional difference may in part explain some of the differences in organic, mineral, and carbonate contents of cetacean bullae relative to those of other bones. The increased density and low organic content of osteosclerotic and pachyosteosclerotic bone (table 1) reduce bone strength (Currey 1979; Pasteris et al. 2008). Although the mineral content of the cetacean bulla's involucrum is greater than those of skeletal bone, tooth cementum, and tooth dentine, it is lower than that of enamel. The cetacean bulla is not a weight-bearing bone, but its intermediate mineral content may reflect the need to accommodate the hydrostatic pressure associated with large volumes of water when cetaceans are feeding. However, it is possible that the bone strength of the cetacean bulla is less affected by functional stresses and strains experienced by other bones in the skeleton because of its location in the head. The synthesis of hydroxyapatite, the dominant mineral in bone and enamel, is biologically "expensive," as it requires phosphorous, often a limiting nutrient. Instead, the involucra of cetacean bullae may substitute greater amounts of carbonate in the bioapatite structure, which increases brittleness and fracture potential but requires only carbon, a biologically abundant element.

Differences in structural composition between the involucra of odontocete and mysticete bullae were surprising and may highlight differences in hearing between these groups. To date, many studies of material properties have focused on mysticete bullae (Lees 1982; de Buffrénil et al. 2004; Mkukuma 2004), but our analysis of an odontocete bulla demonstrates compositional differences between these cetacean groups. For example, the involucrum of the odontocete bulla (Delphinapterus) has a reduced organic content, a higher mineral content, and increased crystallinity, compared to the involucra of mysticete bullae (figs. $3 B, 4$ ). These differences in material properties, coupled with the previously identified morphological adaptations among mysticetes and odontocetes, are consistent with the interpretation that high-frequency sound perception in odontocetes could play a role in cetacean bullar structural design (Ketten 1994). 
Insight into Pachyosteosclerotic Development

Based on Amino Acid Profiles

The compositional pattern of the cetacean bulla involucrum is different from that of terrestrial-artiodactyl bioapatite (fig. $3 \mathrm{~B}$ ). However, there are differences in amino acid composition between the exterior and central portions that likely correspond to development of this unique bioapatite. Histological studies on the ontogeny of cetacean bullae indicate formation in utero, with an exterior mineralized surface and a porous, organic-rich involucrum (the central region; Solntseva 1990; de Buffrénil et al. 2004). The amino acid analysis of one fetal mysticete bulla (Balaena) included the combined exterior and central involucrum but reflected a composition consistent with osteosclerotic and pachyosteosclerotic bone, which supports in utero formation. In contrast, the other three adult mysticete bullae in this study have a clear distinction between the exterior and central involucrum's amino acid composition.

There is a noticeable visual distinction between the involucrum regions within cetacean bullae on a histological section of an odontocete bulla (Delphinapterus; fig. $1 E$ ), which corresponds to the amino acid differences of the "exterior" involucrum (shown in the solid boxes of fig. $1 C$ ). We are confident in limiting the compositional differences to the exterior rind of the involucrum because opportunistic samples of chipped outer bullae had a PC1 value intermediate between those of subsampled regions within the central involucrum and the exterior involucrum + skeletal bones (fig. $2 C$ ). These results conform to previous studies that indicate that the central bulla's involucrum is formed in utero, with a higher organic composition (de Buffrénil et al. 2004; Cozzi et al. 2012). Following birth, exterior and central portions of the bulla are rapidly mineralized during the first 6 mo (de Buffrénil et al. 2004; Cozzi et al. 2012).

Collagen is a fibrous protein with a triple helix structure of polypeptide chains that increases the toughness and strength of bone (Weiner and Wagner 1998; Viguet-Carrin et al. 2005; Fratzl 2008; Hulmes 2008). A primary amino acid in collagen is glycine, which is part of the repeating chain motif Gly-X-Y, where $\mathrm{X}$ and $\mathrm{Y}$ can be any amino acid but are most often proline and hydroxyproline, respectively (Hulmes 2008). The structure of proline and hydroxyproline provides stability along the outer helix, while the small size of glycine is ideal for the central position (Grant and Prockop 1972; Hulmes 2008; Szpak 2011). The approximate composition of proline and hydroxyproline in type I collagen (the most abundant in mammalian bone) totals 20\% (Hulmes 2008), but there are compositional differences among taxa and among bioapatites (Szpak 2011). In particular, mammalian collagen has increased amounts of proline and hydroxyproline and reduced amounts of glycine and serine, relative to collagen in fish (Eastoe 1955; Szpak 2011).

Our comparative analysis of amino acid profiles determined compositional similarities among the central cetacean bullae and other osteosclerotic and pachyosteosclerotic bone (PC1 > 0 ), and amino acid profiles for these bones were found to differ significantly from those of mammalian skeletal bone $(\mathrm{PC} 1<$
0 ; fig. 3C). This variation in amino acid composition suggests that collagen is not the primary organic matrix of osteosclerotic bone, because glycine and hydroxyproline, which are two central amino acids in the collagen structure, are reduced relative to other mammalian skeletal bone. Instead of the expected amino acid pattern for collagen, the organic matrix of osteosclerotic bone has increased glutamic acid, aspartic acid, and alanine-nonessential, glucogenic amino acids that can be biosynthesized and are therefore not limited by dietary intake. Our results indicate that collagen is reduced in the central involucrum of cetacean bulla because this bone is not subjected to stress or strain. Instead, the organic matrix within the central involucrum of cetacean bulla has an increased proportion of easily biosynthesized, nonessential amino acids as a result of rapid growth and development of the organic framework before birth.

The observed difference in amino acid composition could be related to increased bone density. Bones with the greatest density, and therefore the greatest degree of osteosclerosis (i.e., manatee ribs and cetacean bullae), demonstrate a distinct amino acid profile $(\mathrm{PC} 1 \gg 0)$. Furthermore, there are distinctions among the artiodactyl and nonartiodactyl (manatee) pachyosteosclerotic bioapatites: the manatee ribs had substantially greater amounts of proline and lower amounts of arginine than the involucra of cetacean bullae or hippo bioapatites (table A3). The relative density of the hippo bulla compared to the occipital condyle is similar to that of other artiodactyls (O'Leary et al. 2012), but the hippo bulla in this study has a greater crystallite size than other artiodactyl bullae or skeletal bone (fig. 4) and was more resistant during sampling. The amino acid results in this study suggest that the hippo occipital condyle may also have a slightly osteosclerotic condition $(\mathrm{PC} 1=0.006$; fig. $3 C$ ), as both hippo bioapatites cluster with other osteosclerotic bone (fig. 3C; PC1 >0). On the basis of our artiodactyl bioapatite results, we hypothesize that the rostrum of Mesoplodon densirostris, which has the densest bioapatite (Rogers and Zioupos 1999; de Buffrénil et al. 2000; Buckley et al. 2012), will have an amino acid composition similar to that of the osteosclerotic bone in this study. Furthermore, the amino acid composition shared among all osteosclerotic bone is distinct from that of skeletal bone even when compared to other data sets collected from different preparation methods. For example, Szpak (2011) compiled mammalian bone amino acid profiles from eight studies, which included several artiodactyls as well as other mammals (i.e., human, bear, etc.; fig. $3 C$ ).

\section{Conclusions}

This study compared macro- and nanoscale differences among bioapatites from species of Artiodactyla, using XRD, LOI, and amino acid analyses with specimens that included teeth, bullae, and skeletal elements from terrestrial, semiaquatic, and fully aquatic taxa. Our results greatly expand the number of bioapatite specimens analyzed with a single XRD or LOI method and confirm the intermediate composition of the involucrum from cetacean bullae relative to tooth enamel and skeletal bone. 
By comparing the involucrum of cetacean bullae to tooth enamel, hippo bulla, manatee ribs, and skeletal bone, we were able to demonstrate significant differences in organic, mineral, and carbonate content as well as large differences in CI and crystallite size. Furthermore, our results suggest compositional differences between the central and exterior involucrum of cetacean bullae. Central involucrum specimens from cetacean bullae have an amino acid profile distinct from that of artiodactyl skeletal bone but similar to that of other pachyostotic or osteosclerotic bone (i.e., hippo bullae and manatee ribs). Finally, the involucra of odontocete bullae (both exterior and central areas) have higher CIs and larger crystallite sizes than do those of mysticetes; this may be related to high-frequency and directional hearing.

These results support the presence of an aquatic lifestyle before the origin of the order Cetacea and suggest that these developmental adaptations may extend to the common ancestor of the Cetacea-Raoellidae-Hippopotamidae clade. Alternatively, the similarities in amino acid composition between osteosclerotic bones within Artiodactyla and Sirenia, two distantly related mammalian clades (fig. 2), as well as the lack of resorption and remodeling in these bones (de Buffrénil et al. 2004, 2010), suggest a developmental "blueprint" within Mammalia for osteosclerotic bone construction, a condition within taxa that is often associated with aquatic environments.

\section{Acknowledgments}

We thank Jeremy McGowen, David Perry, and Norbert Swoboda-Colberg for data collection assistance. We also thank the University of Wyoming Vertebrate Paleontology Collections and Vertebrate Museum for allowing us to sample specimens in their collections. Delphinapterus specimens were collected by the Department of Wildlife Management, North Slope Borough, Barrow, Alaska, with permission from the Alaska Beluga Whale Committee under NOAA-NMFS (National Oceanic and Atmospheric Administration-National Marine Fisheries Service) permit 814-1899-01. We thank the people of Point Lay, Alaska, for their help and three anonymous reviewers for their constructive feedback. This research was conducted under NMFS permit 493-1848/MA130062 and funded by the National Science Foundation (EAR SGP 0847413 to M.T.C.).

\section{Literature Cited}

Barklow W.E. 2004. Amphibious communication with sound in hippos, Hippopotamus amphibius. Anim Behav 68:11251132.

Buckley K., P. Matousek, A.W. Parker, and A.E. Goodship. 2012. Raman spectroscopy reveals differences in collagen secondary structure which relate to the levels of mineralisation in bones that have evolved for different functions. J Raman Spectrosc 43:1237-1243.

Carter D.R. and W.C. Hayes. 1976. Bone compressive strength: influence of density and strain rate. Science 194:1174-1176.
Champe P.C., R.A. Harvey, and D.R. Ferrier. 2008. Biochemistry. 4th ed. Lippincott's Illustrated Reviews. Lippincott, Williams \& Watkins, New York.

Cho G., Y. Wang, and J.L. Ackerman. 2003. Detection of hydroxyl ions in bone mineral by solid-state NMR spectroscopy. Science 300:1123-1127.

Cozzi B., M. Podestà, S. Mazzariol, and A. Zotti. 2012. Fetal and early post-natal mineralization of the tympanic bulla in fin whales may reveal a hitherto undiscovered evolutionary trait. PLoS ONE 7:e37110.

Currey J.D. 1979. Mechanical properties of bone tissues with greatly differing functions. J Biomech 12:313-319.

- 1999. The design of mineralised hard tissues for their mechanical functions. J Exp Biol 202:3285-3294.

Danilchenko S.N., O.G. Kukharenko, C. Moseke, I.Y. Protsenko, L.F. Sukhodub, and B. Sulkio-Cleff. 2002. Determination of the bone mineral crystallite size and lattice strain from diffraction line broadening. Cryst Res Technol 37:12341240.

de Buffrénil V., A. Canoville, R. D’Anastasio, and D.P. Domning. 2010. Evolution of sirenian pachyosteosclerosis, a model-case for the study of bone structure in aquatic tetrapods. J Mammal Evol 17:101-120.

de Buffrénil V., W. Dabin, and L. Zylberberg. 2004. Histology and growth of the cetacean petro-tympanic bone complex. J Zool 262:371-381.

de Buffrénil V., L. Zylberberg, W. Traub, and A. Casinos. 2000. Structural and mechanical characteristics of the hyperdense bone of the rostrum of Mesoplodon densirostris (Cetacea, Ziphiidae): summary of recent observations. Hist Biol 14: 57-65.

Dixon P. 2003. VEGAN, a package of $\mathrm{R}$ functions for community ecology. J Veg Sci 14:927-930.

Eastoe J. 1955. The amino acid composition of mammalian collagen and gelatin. Biochem J 61:589.

El Feki H., J. Savariault, and A. Ben Salah. 1999. Structure refinements by the Rietveld method of partially substituted hydroxyapatite: $\mathrm{Ca}_{9} \mathrm{Na}_{0.5}\left(\mathrm{PO}_{4}\right)_{4.5}\left(\mathrm{CO}_{3}\right)_{1.5}(\mathrm{OH})_{2}$. J Alloys Compd 287:114-120.

Fratzl P. 2008. Introduction. Pp. 1-13 in P. Fratzl, ed. Collagen: structure and mechanics. Springer, New York.

Grant M.E. and D.J. Prockop. 1972. The biosynthesis of collagen. N Engl J Med 286:194-199.

Heiri O., A.F. Lotter, and G. Lemcke. 2001. Loss on ignition as a method for estimating organic and carbonate content in sediments: reproducibility and comparability of results. J Paleolimnol 25:101-110.

Hemilä S., S. Nummela, and T. Reuter. 2010. Anatomy and physics of the exceptional sensitivity of dolphin hearing (Odontoceti: Cetacea). J Comp Physiol A 196:165-179.

Hulmes D. 2008. Collagen diversity, synthesis and assembly. Pp. 15-48 in P. Fratzl, ed. Collagen: structure and mechanics. Springer, New York.

Ketten D.R. 1992. The marine mammal ear: specializations for aquatic audition and echolocation. Pp. 717-750 in D.B. Web- 
ster, R.R. Fay, and A.N. Popper, eds. The evolutionary biology of hearing. Springer, New York.

- 1994. Functional analyses of whale ears: adaptations for underwater hearing. IEEE Underw Acoust 1:264-270.

- 2000. Cetacean ears. Pp. 43-108 in W.W.L. Au, A.N. Popper, and R.R. Fay, eds. Hearing by whales and dolphins. Springer, New York.

Koopman H.N., S.M. Budge, D.R. Ketten, and S.J. Iverson. 2006. Topographical distribution of lipids inside the mandibular fat bodies of odontocetes: remarkable complexity and consistency. IEEE J Ocean Eng 31:95-106.

Lees S. 1982. Ultrasonic measurements of deer antler, bovine tibia and tympanic bulla. J Biomech 15:867-874.

Loong C.K., C. Rey, L.T. Kuhn, C. Combes, Y. Wu, S.H. Chen, and M.J. Glimcher. 2000. Evidence of hydroxyl-ion deficiency in bone apatites: an inelastic neutron-scattering study. Bone 26:599-602.

Mkukuma L.D.E.A. 2004. Effect of the proportion of organic material in bone on thermal decomposition of bone mineral: an investigation of a variety of bones from different species using thermogravimetric analysis coupled to mass spectrometry, high-temperature X-ray diffraction, and Fourier transform infrared spectroscopy. Calcif Tissue Int 7:321-328.

Nummela S., J. Thewissen, S. Bajpai, S. Hussain, and K. Kumar. 2004. Eocene evolution of whale hearing. Nature 430:776778.

- 2007. Sound transmission in archaic and modern whales: anatomical adaptations for underwater hearing. Anat Rec 290:716-733.

Nummela S., T. Wägar, S. Hemilä, and T. Reuter. 1999. Scaling of the cetacean middle ear. Hear Res 133:71-81.

O’Leary M.A., B.A. Patel, and M.N. Coleman. 2012. Endocranial petrosal anatomy of Bothriogenys (Mammalia, Artiodactyla, Anthracotheriidae), and petrosal volume and density comparisons among aquatic and terrestrial artiodactyls and outgroups. J Paleontol 86:44-50.

Pasteris J.D., B. Wopenka, J.J. Freeman, K. Rogers, E. ValsamiJones, J.A.M. van der Houwen, and M.J. Silva. 2004. Lack of $\mathrm{OH}$ in nanocrystalline apatite as a function of degree of atomic order: implications for bone and biomaterials. Biomaterials 25:229-238.

Pasteris J.D., B. Wopenka, and E. Valsami-Jones. 2008. Bone and tooth mineralization: why apatite? Elements 4:97-104.

Person A., H. Bocherens, J.F. Saliège, F. Paris, V. Zeitoun, and M. Gérard. 1995. Early diagenetic evolution of bone phosphate: an X-ray diffractometry analysis. J Archaeol Sci 22: 211-221.
R Core Development Team. 2008. R: a language and environment for statistical computing. R Foundation for Statistical Computing, Vienna.

Rey C., J.L. Miquel, L. Facchini, A.P. Legrand, and M.J. Glimcher. 1995. Hydroxyl groups in bone mineral. Bone 16:583586.

Rogers K.D. and P. Zioupos. 1999. The bone tissue of the rostrum of a Mesoplodon densirostris whale: a mammalian biomineral demonstrating extreme texture. J Mater Sci Lett 18: 651-654.

Shemesh A. 1990. Crystallinity and diagenesis of sedimentary apatites. Geochim Cosmochim Acta 54:2433-2438.

Solntseva G.N. 1990. Formation of an adaptive structure of the peripheral part of the auditory analyzer in aquatic, echolocating mammals during ontogenesis Pp. 363-383 in J.A. Thomas and R.A. Kastelein, eds. Sensory abilities of cetaceans: laboratory and field evidence. Plenum, New York.

Spaulding M., M.A. O'Leary, and J. Gatesy. 2009. Relationships of Cetacea (Artiodactyla) among mammals: increased taxon sampling alters interpretations of key fossils and character evolution. PLoS ONE 4:e7062.

Szpak P. 2011. Fish bone chemistry and ultrastructure: implications for taphonomy and stable isotope analysis. J Archaeol Sci 38:3358-3372.

Thewissen J.G.M., L.N. Cooper, M.T. Clementz, S. Bajpai, and B.N. Tiwari. 2007. Whales originated from aquatic artiodactyls in the Eocene epoch of India. Nature 450:1190-1194.

Thewissen J.G.M., L.N. Cooper, J.C. George, and S. Bajpai. 2009. From land to water: the origin of whales, dolphins, and porpoises. Evol Educ Outreach 2:272-288.

Viguet-Carrin S., P. Garnero, and P.D. Delmas. 2005. The role of collagen in bone strength. Osteoporosis Int 17:319-336.

Wartzok D. and D.R. Ketten. 1999. Marine mammal sensory systems. Pp. 117-175 in J. Reynolds and S. Rommel, eds. Biology of marine mammals. Smithsonian Institution Press, New York.

Weiner S. and H.D. Wagner. 1998. The material bone: structuremechanical function relations. Annu Rev Mater Sci 28:271298.

Wopenka B. and J.D. Pasteris. 2005. A mineralogical perspective on the apatite in bone. Mater Sci Eng 25:131-143.

Yamato M., D.R. Ketten, J. Arruda, S. Cramer, and K. Moore. 2012. The auditory anatomy of the minke whale (Balaenoptera acutorostrata): a potential fatty sound reception pathway in a baleen whale. Anat Rec 295:991-998. 